\title{
Impact of Obesity in Non-Alcoholic Fatty Liver Disease
}

\section{Chanjugaa Uthayakumar, Supeshala Kotalawala}

Department of Applied Science, Northumbria University, New Castle, United Kingdom

Correspondence to: Chanjugaa Uthayakumar, Chanjubms@gmail.com

Keywords: Non-Alcoholic Fatty Liver Disease, Obesity, Diabetes, Cardiovascular Diseases, Insulin Resistance Metabolic Syndrome and Biopsy

Received: April 4, 2019 Accepted: February 1, $2021 \quad$ Published: February 4, 2021

Copyright $\odot 2021$ by author(s) and Scientific Research Publishing Inc.

This work is licensed under the Creative Commons Attribution International License (CC BY 4.0).

http://creativecommons.org/licenses/by/4.0/

\section{(c) (i) Open Access}

\section{ABSTRACT}

"Non-alcoholic fatty liver disease" is the alarming health risk around the world today. Nearly $1 / 3$ of the world's population is affected by non-alcoholic fatty liver disease. Many scientists put forward two hit hypotheses to explain the pathophysiology of non-alcoholic fatty liver disease. With the aid of trials using Biopsy, ultrasound scan and molecular techniques, scientists explained an authentic evidence of non-alcoholic fatty liver disease progression is ultimately because of obesity and its commodities, such as Cardio vascular diseases, Diabetes and Metabolic syndrome. This review mainly focuses on how obesity leads to non-alcoholic fatty liver disease based on statistical analysis of different research studies conducted by the research scientists. In the analysis of 1980-2003, out of 505 individuals, 305 were affected with NAFLD and among them, $64.3 \%$ were obese. In the analysis of the period of 1996-2002, out of 550 NAFLD patients, $70.36 \%$ were obese. Also in the analysis of 2010-2015 period of time, mostly $90 \%$ of the NAFLD patients were obese. It was also revealed that, along with NAFLD and obesity, diabetes and hyperlipidemia also exist as the commodities of obesity. Attention of medical field is towards the treatment and analysis of non-alcoholic fatty liver disease which is expected to be the reason of liver transplant by 2020 .

\section{INTRODUCTION}

Non-alcoholic fatty liver disease (NAFLD) is a hallmark of steatosis and a major challenge for liver abnormalities and gastroenterology today [1-3]. In 1980, NAFLD was introduced to the world for the very first time by Ludwig and his colleagues. In literature, NAFLD plays a vital role in morbidity and mortality along with no signs and symptoms [4]. It encompasses with 4 stages beginning with simple steatosis (see Table 1).

It was estimated that in the general population, $10 \%$ to $30 \%$ are affected by NAFLD. The clinical investigations of NAFLD always depend on natural history and prevalence worldwide. Subsequently, several researches highlight that basic reason for NAFLD is obesity [5]. 
Table 1. Stages of non-alcoholic fatty liver disease.

\begin{tabular}{llc}
\hline \multicolumn{1}{c}{ Stages } & \multicolumn{1}{c}{ Description } & Reference \\
\hline $\begin{array}{l}\text { 1) Simple steatosis } \\
\text { 2) Non-alcoholic } \\
\text { steatohepatitis (NASH) }\end{array}$ & $\begin{array}{l}\text { Harmless accumulation of fats in hepatocytes } \\
\text { The liver becomes inflamed because of more } \\
\text { and more fat accumulation }\end{array}$ & {$[4-6]$} \\
3) Liver fibrosis & $\begin{array}{l}\text { Formation of scar tissue around the inflamed } \\
\text { hepatic tissues and nearby blood vessels }\end{array}$ & {$[4,7,8]$} \\
& $\begin{array}{l}\text { Final stage of NAFLD this severe stage occurs after many years } \\
\text { of inflammation finally leading to liver failure. } \\
\text { P) Liver cirrhosis }\end{array}$ & {$[4,9,10]$} \\
& Permanent damage to liver. & {$[1,12,13]$}
\end{tabular}

Also, Obesity is considered as the gateway for other comorbidities such as malignancies, cardio vascular diseases (CVD), metabolic syndrome (MS), diabetes mellitus (DM), hypertension and insulin resistance (IR) which were the main risk factors for the progression of the condition called NAFLD [14-17].

\section{OBESITY}

Obesity has become a pandemic concern along with its rapidly progressing prevalence around the world [18]. Obesity is the increased Body Mass Index (BMI). BMI threshold values are used worldwide to categorize individuals in to different groups as shown in Table 2.

BMI reflects excess fat accumulation around the body [19]. In United States, for obesity the BMI cutoff value is defined as $30 \mathrm{Kg} / \mathrm{M}^{2}$. It may vary depending on race and phenotypic classifications [20]. According to WHO, Obesity has risen intensely affecting both children and adult. 1/3 of the population is obese. Among them 39\% are adults, 41 million are children. This clearly illustrates the progression of obesity around the world [18].

\section{TWO HIT HYPOTHESES}

Overall scientific literature shows cases, that the origin of NAFLD is multifactorial [21]. Though the pathology of NAFLD is still unknown, according to many research articles its pathology is defined by two hit hypotheses $[11,22,23]$. According to Croke and Sampson (2012), the first hit hypothesis is due to Metabolic syndrome, Insulin resistance and later on to CVD. This leads to the surge in the levels of free fatty acids in liver [24]. The surge, causes the impairment of filtration of fatty acids in liver eventually leads to apoptosis, steatosis and NAFLD [25].

Since one hypothesis is not enough to conclude the pathophysiology of NAFLD, Maheshwari and Thuluvath (2006), states that the first hit hypothesis and its impact on liver leads to many factors such as oxidative stress, diabetes, mitochondrial dysfunction and inflammatory cytokine reactions that defines the second hit hypothesis [26].

\section{RISK FACTORS OF NAFLD UNDERLINED OBESITY}

Subsequently several researches have stated that these hypotheses which highlights IR, DM, inflammatory cytokines and fatty acid accumulation in liver ultimately from obesity and the correlation with these factors and NAFLD $[9,23,27]$.

According to Charlton et al (2011) NASH and NAFLD are acknowledged as the main attestation for liver transplantation and also will be anticipated as the governing cause of liver transplantation by 2020 . 
Table 2. WHO classification of BMI and obesity [19].

\begin{tabular}{ccc}
\hline Classification & \multicolumn{2}{c}{ BMI $\left(\mathrm{kg} / \mathrm{m}^{2}\right)$} \\
\hline Underweight & $<18.50$ & $<18.50$ \\
Severe thinness & $<16.00$ & $<16.00$ \\
Moderate thinness & $16.00-16.99$ & $16.00-16.99$ \\
Mild thinness & $17.00-18.49$ & $17.00-18.49$ \\
Normal range & $18.50-24.99$ & $18.50-22.99$ \\
Overweight & $\geq 25.00$ & $23.00-24.99$ \\
Pre-obese & $25.00-29.99$ & $\geq 25.00$ \\
Obese & $\geq 30.00$ & $25.00-27.49$ \\
\hline
\end{tabular}

American journal of gastroenterology reported along with the investigations of majority of population through ultrasound scan testing, it was revealed that NAFLD is progressing worldwide because of obesity and its comorbidities such as metabolic syndrome, diabetes mellitus, insulin resistance and cardio vascular diseases $[20,28]$.

"National health and nutrition examination survey" which was conducted in 1988-1994, also emphasized that $1 / 3$ of the population were subjected with NAFLD and among them $90 \%$ of subjects were obese [29]. Major risk factor of NAFLD is obesity and this obesity is due to the contribution of multiple factors such as genetic background, lifestyle, food patterns and environmental factors as well $[11,22]$. To analyze the impact of obesity in NAFLD since the concomitance of obesity with IR, metabolic syndrome, T2DM, and inflammatory cytokines, many research articles were based on imaging, laboratory and histological findings. While the patients were ruled out of consuming alcohol or other drugs [30].

Obesity due to excess visceral adiposity along with lectin which is a product and responsible gene of obesity, involves in a dramatic role in modulation of insulin sensitivity whereas leading to insulin resistance and T2DM $[1,31]$.

Studies also support that obesity and high calorie intake leads to hepatic insulin resistance. This excess accumulation of fatty acids leads to chronic inflammation around the outlying adipose tissues, which directs to metabolic syndrome and surge in "inflammatory cytokines" such as TNF-alpha, IL-8, IL-6, CRP, MCP and some decreased levels of "anti-inflammatory adipokines" such as IL-10 and adiponectin leading to insulin resistance [31].

Odegaard and Chawla (2008), via testing bacteria and parasite about the innate immune modulation in obesity also supports that this surge in the levels of inflammatory cytokines and decreased levels of anti-inflammatory adipokines is the natural phenomenon in the development of insulin resistance (IR) and gradually to diabetes mellitus (DM).

Fatty acid accumulation in liver underlined obesity also promotes peroxisomal and mitochondrial $\beta$-oxidation which enhances microsomal induction of both CYP2E1 and CYP4A1 [31]. Also in the consecutive year [32] sates that this microsomal induction leads to the increased reactive oxygen species in liver promoting mitochondrial dysfunction, steatohepatitis and eventually to NAFLD. According to a study by [33], the mortality in NAFLD patients was due to CVD and malignancy. This study also states that these people were exposed to an obesity risk factor that progressed towards developing T2DM as well.

Table 3 below shows the demographic details of patients with NAFLD around 1980-2003. These studies states that NAFLD is more frequent in females, these studies also showcase with higher prevalence of obesity and the frequent prevalence of T2DM respectively. 
Table 3. Trials of NAFLD and risk factors obesity and diabetics.

\begin{tabular}{ccccc}
\hline $\begin{array}{c}\text { Journal } \\
\text { Author }\end{array}$ & $\begin{array}{c}\text { Number of patients } \\
\text { with NFLD }\end{array}$ & $\begin{array}{c}\text { Percentage of female } \\
\text { with NAFLD }\end{array}$ & $\begin{array}{c}\text { Percentage of } \\
\text { obesity }\end{array}$ & $\begin{array}{c}\text { Percentage of } \\
\text { Diabetes }\end{array}$ \\
\hline$[34]$ & 20 & $65 \%$ & $90 \%$ & $25 \%$ \\
{$[4]$} & 49 & $78 \%$ & $69 \%$ & $51 \%$ \\
{$[12]$} & 42 & $83 \%$ & $93 \%$ & $36 \%$ \\
{$[35]$} & 90 & $51 \%$ & $87 \%$ & $46 \%$ \\
{$[36]$} & 104 & $17 \%$ & $25 \%$ & $7 \%$ \\
\hline
\end{tabular}

The above statistical analysis illustrates a clear picture that, among 505 individuals in the study, 305 were affected with NAFLD. Obesity is in its peak around $64.3 \%$ and diabetes around $21 \%$ but in those studies, it was also mentioned, there were individuals who developed diabetes as the ultimate reason of obesity [36]. Evidences also show that individuals who were diabetic also developed NAFLD later [4].

A study conducted by Blackett and Sanghera (2016) states that NAFLD is strongly linked with obesity resulting in metabolic syndrome, diabetes and CVD. These trials also emphasize mortality rates of NAFLD are due to developed CVD as a risk factor. It also states that NAFLD is strongly linked with obesity resulting in metabolic syndrome, diabetes and cardio vascular diseases. These trials also emphasize mortality rates of NAFLD patients, due to CVD was high which was also a risk factor of NAFLD [37] (Table 4).

There are so many trials which were tested to analyze the impact of obesity in non-alcoholic fatty liver disease since it also creates so many risk factors such as diabetes and, metabolic syndrome due to hyperlipidemia. As shown in Table 5 below, almost in all trials the above said risk factors were observed simultaneously which gave a clear picture that NAFLD was the ultimate cause of obesity. Since obesity was elicited in a higher percentage of the populations tested $[1,22]$.

\section{VALUATION OF NAFLD AROUND THE WORLD}

Statistically $30 \%$ of the general population in the world was affected by NAFLD $[4,47]$. Numerous investigations have revealed the possible association of NAFLD for higher rates of mortality today. Nevertheless, obesity underlined risk factors such as CVD, IR, metabolic syndrome, inflammation and hepatic carcinoma, increases the progression of NAFLD [22,31].

According to WHO calorie intake and obesity seemed to be double from 1980 . Rafiq and his colleagues (2009) also state that 39\% of NAFLD adult patients around the world were obese. Rinella and Charlton (2016) emphasizes that USA was in the center position of Obesity and NAFLD [21, 31].

\subsection{USA and NAFLD}

Younossi and his colleagues (2016) analyzed 70 reports published around 1989-2015 consisted with a specific sample size $(8,515,431)$ from 22 different countries which emphasizes that $28.65 \%$ - 30\% of population around the world were affected by NAFLD and with a higher prevalence in USA along with increased obesity [29].

A cohort study states that prevalence of NAFLD at USA was increased by a factorial of 2.8 within the period of 9 years (2003-2011). This also mentioned NAFLD will continue to be a major risk along with increased rate of obesity [49].

A biopsy study and constant monitoring in 20 obese patients suspected of NAFLD within the period of 1985-2001, along with ethnic diversities such as Caucasians-59\%, Hispanics-36\%, African American 5\%. Among the individuals $64 \%$ were with hyperlipidemia and $41 \%$ were with diabetes. This study highlighted that all individuals were affected with NAFLD and the biopsy images revealed the fibrous liver in the last year of examination [50]. 
Table 4. Some trials of NAFLD underlined Obesity with the risk of CVD.

\begin{tabular}{|c|c|c|c|c|}
\hline Year & Method & Population (n) & Findings & Reference \\
\hline 2010 & MRI evaluation & $\begin{array}{c}\mathrm{n}=66, \text { American } \\
\text { pediatric population }\end{array}$ & $\begin{array}{l}100 \% \text { obese Along with } \\
\text { high VLDL concentration } \\
\text { and increased CVD risks }\end{array}$ & [38] \\
\hline 2010 & Liver biopsy & $\begin{array}{l}\mathrm{n}=118, \text { Swedish } \\
\text { NAFLD patients }\end{array}$ & $\begin{array}{l}\text { Increased morality of } \\
\text { NAFLD patients due to } \\
\text { CVD } 90 \% \text { are obese }\end{array}$ & [39] \\
\hline 2013 & $\begin{array}{l}\text { Liver biopsy MRS } \\
\text { Endocardiography }\end{array}$ & $\begin{array}{l}\text { Adults population } \\
\text { based study }\end{array}$ & $\begin{array}{l}\text { At MRI n = } 54 \text { with obese and } \\
\text { intrahepatic try glyceride was } \\
\text { high, worse systolic and } \\
\text { diastolic functions }\end{array}$ & {$[31]$} \\
\hline 2012 & $\begin{array}{l}\text { Endo cardiograph, } \\
\text { and ultra sound scan test }\end{array}$ & $\mathrm{n}=165$ & $\begin{array}{l}\mathrm{N}=97 \text { were obese and showed } \\
\quad \text { elevated levels of amino } \\
\text { transferases along with systolic } \\
\text { and diastolic dysfunction }\end{array}$ & {$[40]$} \\
\hline 2015 & $\begin{array}{c}\text { Systemic } \\
\text { literature search }\end{array}$ & $\begin{array}{l}12 \text { studies, } 9 \text { were } \\
\text { adults' population } \\
\text { based and } 3 \text { were } \\
\text { pediatric studies }\end{array}$ & $\begin{array}{l}\text { Children and adults were obese and } \\
\text { had NAFLD along with CVD }\end{array}$ & {$[41]$} \\
\hline
\end{tabular}

Table 5. Trials of NAFLD underlined obesity and its risk factors.

\begin{tabular}{cccccc}
\hline Reference & Year & Number of NAFLD Patients & Diabetes (\%) & Obesity (\%) & Hyper lipidemia (\%) \\
\hline$[42]$ & 1996 & 40 & 36 & 70 & 38 \\
{$[43]$} & 1999 & 134 & 38 & 70 & 32 \\
{$[44]$} & 1999 & 144 & 18 & 60 & 37 \\
{$[16]$} & 1999 & 30 & 43 & 80 & 13 \\
{$[35]$} & 2001 & 90 & 46 & 87 & 61 \\
{$[45]$} & 2002 & 66 & 35 & 67 & 82 \\
{$[46]$} & 2002 & 46 & 34 & 72 & 34 \\
\hline
\end{tabular}

Trials based on the impact of obesity in NAFLD individuals around 2005 showed a clear-cut evidence. ALT level analysis of 4376 individuals revealed $41.1 \%$ were obese and among the obese $7 \%$ were affected by NAFLD [51]. CT scan analysis of $\mathrm{n}=742$ population based study elicited $68.6 \%$ were affected with NAFLD and among those individuals $39.1 \%$ were obese [52].

A study conducted by Laurin and his colleagues (1996) at USA along with 2287 obese patients' states that, prevalence of NAFLD varied according to ethnicity. Whereas $45 \%$ of them are Hispanics, $24 \%$ were 
blacks and 33\% were whites. Nevertheless, this study has a profound impact on NAFLD underlined obesity [42].

Data obtained in America within the period of 1999-2002 and 2009-2012 were analyzed by "National health and nutrition examination survey" on NAFLD underlined fibrosis and obesity [20]. This survey elicits a significant increase in diabetes, IR and obesity as well. All the data were under the p value of 0.005 . The percentages of the above-mentioned risk factors were given below [19].

Among American adults from 1999-2002 obesity was $29.8 \%$ which turned significantly high around $2009-2012$ as $36.6 \%$. Whereas percentage of diabetes from $1999-2002$ was $8.3 \%$ which also showed the rate of elevation up to $11.9 \%$ around 2009-2012 [19]. Also from 1999-2002 insulin resistance was $34.7 \%$ which was also elevated up to $42.1 \%$ in $2009-2012$ periods of study. This clearly gives an overview of the progression of NAFLD ultimately because of the higher rate of obesity prevailing in USA $[19,39,51,53]$.

At present obesity and diabetes were the alarming risk factors of the progression of NAFLD in USA. Some of the trials emphasizes that there was a difference in the progression of NAFLD based on ethnicity as well [54].

As shown in Figure 1, the statistical data shows $60 \%-76 \%$ of NASH and $22 \%$ of NAFLD could be observed in diabetic patients in USA. T2DM also prevailing as the independent risk factor for NAFLD, NASH and hepatic carcinoma which reflects high calorie intake or obesity in USA [28].

The survey of "International Diabetic Federation" illustrates $10.7 \%$ of the adults were affected by diabetes and NAFLD in Caribbean islands and Northern America. Also, it emphasizes obesity leads to T2DM and to metabolic syndrome which noticed in 20\%-80\% of NAFLD, diabetic and along with obese patients [14]. Ethnicity also plays as a predictor of NAFLD. Many trials in America prove that there is a difference in progression of NAFLD based on ethnicity. Statistics also illustrates among Americans, Hispanics shows the higher rate of NAFLD [55]. Adult population based study of 1,026 individuals also highlights that Hispanics were highly affected than the African American or other ethnic diversities in USA [56].

Almost all trials in USA concludes that based on the rate of obesity, NAFLD rates estimated to be $29 \%$ in USA, 28\% in Belize, 28\% in Barbados, 28\% in Mexico, 24\% in Venezuela and 20\% in Uruguay [14, 55, 57].

\subsection{Impact of Obesity around UK, China, Italy and Srilanka}

A biopsy study of 108 NAFLD patients in UK for about 6 years showed 42\% with severe NAFLD, 40\% were stable with initial NAFLD and $18 \%$ were with progression of severe fibrosis [57]. A meta-analysis of a pediatric study at UK, show cases that most of the children were obese and showed the elevation of transaminase levels in their blood samples collected. The levels are to be more than 40UL and around $41 \%$ - 89\%, which elicits the prevalence of NAFLD along with Obesity [3, 32].

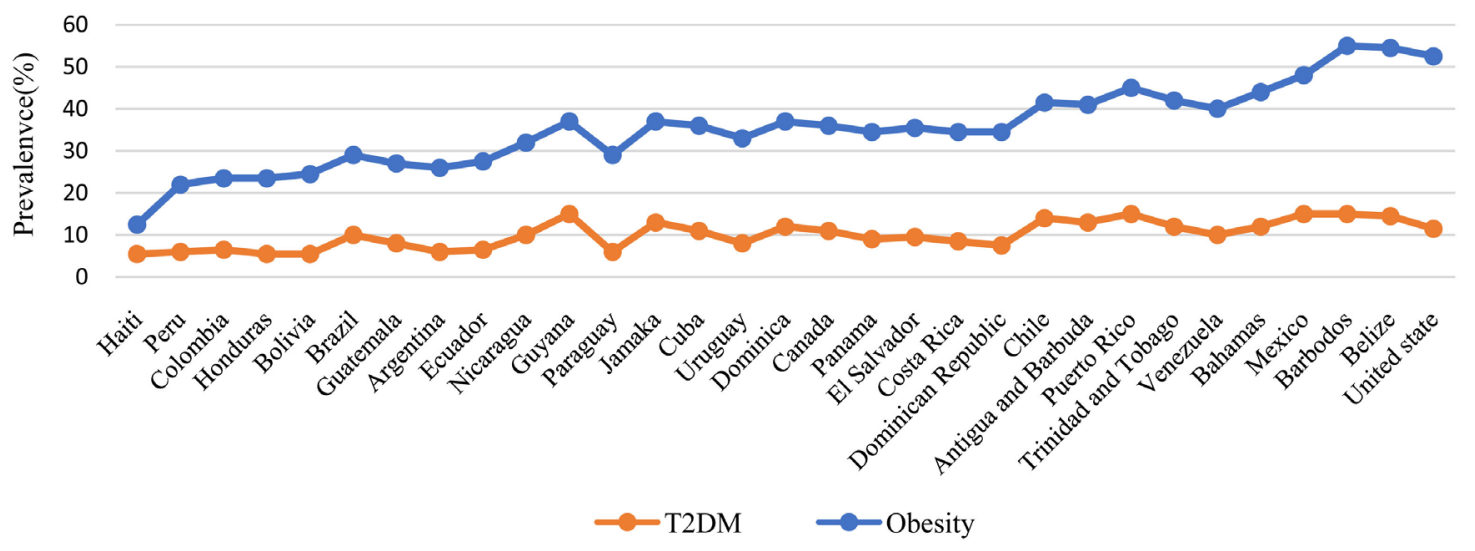

Figure 1. Illustrate the prevelence of T2DM and obesity around America $[14,48,55]$. 
A study conducted in Italy with randomly selected 992 individuals were examined with ultrasound scan, parameters of amino transferases and also physical examination elicits 412 individuals (41.5\%) were obese. Among this study population $24.8 \%$ were presented with NAFLD, $34.4 \%$ with metabolic syndrome and $34.4 \%$ were presented with diabetes. It was also emphasized that these individuals affected with NAFLD and obesity were in the higher risk of developing cardio vascular diseases. Since the study population had $34.7 \%$ hypertension and $34.2 \%$ with hyperlipidemia [31].

Interestingly a study conducted at china based on women suspected to develop NAFLD after post menopause. 4218 post-menopausal women were selected for this trial. Among the study population it was revealed that $32.5 \%(n=1370)$ were affected with NAFLD. Overweight and obesity was noticed as $54.2 \%$ and $49.8 \%$ respectively. Insulin resistance in these individuals were noticed round $27.7 \%$ which gave an evidence that post-menopausal women also have the higher risks of developing NAFLD underlined obesity and its commodities as well [30].

Developing countries also now analyze the NAFLD and its prevalence which is asymptomatic in many individuals. An adult study population of 3012 participants was selected for a trial at Srilanka with the collaboration of "International Center of Japan" (IMCJ). This study population consisted with different ethnic diversities of Sinhalese (34.9\%), Tamils (30.6\%) and Muslims (33.3\%). NAFLD was observed in $31.6 \%$ of men and $37.5 \%$ of women among the study population. Further investigations revealed $70.3 \%$ were obese [58].

\section{ONGOING STUDIES RELATED TO NAFLD}

Ongoing studies are focused on the genetic background of NAFLD. Some trials also emphasize that progression of NAFLD is due to variation in PNPLA3 gene which was responsible for breakdown of fats in liver. Due to this variation of PNPLA3 gene it leads to increased production of PNPLA3 and decreased fat breakdown eventually leading to fat accumulation in liver and obesity. Alteration of HIPK 3, AQP9 and TNNI3 also leads to obesity. However, this whole mechanism was not fully understood and the research is still ongoing [30].

\section{TREATMENT}

In treatment of NAFLD the first line was always based on lifestyle modifications which include exercise and dietary modifications which help the patient to lose weight. It was stated that if the patient reduces the weight by $5 \%$ it showed much improvement in the damaged liver due to NAFLD [59, 60]. Treatment strategies also focused on central appetite suppressants such as Rimonabant, which was an antagonist of cannaboid receptor [61]. Measures are also taken to slow the absorption, drug therapies for insulin resistance, hyper cholesterol levels and diabetes mellitus as well. Different types of bariatric surgeries are also done in patients with NAFLD [48].

Scientists are working on the future development of NAFLD therapy that mainly focus on insulin sensitizing agents that could target PPAR agonists which also reduces the risk of diabetes, bile acid metabolism to reduce the fat accumulation in the liver, induce fat breakdown and filtration of fats in liver. Scientists also focus on anti-inflammatory drugs and anti-fibrotic drugs which could reduce the rate of formation of fibrosis mechanism in liver [28]. Fascinatingly some of the studies also revealed that caffeine in coffee could decrease the rate of liver damage and fibrin formation in hepatocytes [49].

\section{SUMMARY}

This review analyzed the relationship between obesity and NAFLD. From the trials briefed in this review, it is clearer that NAFLD's ultimate reason is obesity. Obesity leads to insulin resistance, metabolic syndrome, diabetes, cardio vascular diseases and malignancies which were the major risk factors of NAFLD. This review also emphasizes that $1 / 3$ of the world's population was affected by NAFLD which is asymptomatic. Pathophysiology of the condition of NAFLD could be explained by two hit hypotheses. 
Literature and statistics elicits majority of the NAFLD patients were obese, who later develops its commodities as diabetes and cardiovascular diseases. Statistics also states that NAFLD will be the major reason for liver transplantation in future world. It also states that NAFLD will be the ultimate reason for the hepatic carcinoma by 2020. Moreover, according to the statistical analysis of this review, it shows cases that majority of pediatric population around the world is affected by obesity because of the consumption of junk foods and soft drinks, which leads them to develop NAFLD and comorbidities of obesity. Since treatment and diagnosis were available for NAFLD, much attention should be given to reduce the rate of progression of NAFLD which is a major health risk hidden in the population today.

\section{CONFLICTS OF INTEREST}

The authors declare no conflicts of interest regarding the publication of this paper.

\section{REFERENCES}

1. Chan, W.K., Hilmi, N.D.A., Cheah, P.L. and Goh, K.L. (2014) Progression of Liver Disease in Non-Alcoholic Fatty Liver Disease: A Prospective Clinicopathological Follow-Up Study. Journal of Digestive Diseases, 15, 542-552. https://doi.org/10.1111/1751-2980.12175

2. Lomonaco, R., Ortiz-Lopez, C., Orsak, B., Webb, A., Hardies, J., Darland, C., Finch, J., Gastaldelli, A., Harrison, S., Tio, F. and Cusil, K. (2012) Effect of Adipose Tissue Insulin Resistance on Metabolic Parameters and Liver Histology in Obese Patients with Nonalcoholic Fatty Liver Disease. Hepatology, 55, 5-7. https://doi.org/10.1002/hep.25539

3. Mc Collough, A.J. and George, B.G. (2016) Natural History of Nonalcoholic Fatty Liver Disease, Hepatology, 2, 54-58.

4. Ludwig, J., Viggiano, T.R., McGill, D.B. and Oh, B.J. (1980) Nonalcoholic Steatohepatitis: Mayo Clinic Experiences with a Hitherto Unnamed Disease. Journal of Gastroenterology and Hepatology, 55, 434-438.

5. Maheshwari, A. and Thuluvath, P.J. (2011) Endocrine Disease and the Liver. Clinics in Liver Disease, 15, 55-67. https://pubmed.ncbi.nlm.nih.gov/21111993 https://doi.org/10.1016/j.cld.2010.09.008

6. Adams, L.A., Zein, C.O., Angulo, P. and Lindor, K.D. (2004) A Pilot Trial of Pentoxifylline in Nonalcoholic Steatohepatitis. American Journal Gastroenterology, 99, 2365-2368.

https://doi.org/10.1111/j.1572-0241.2004.40064.x

7. Rafiq, N., Bai, C., Fang, Y., Srishord, M., McCullough, A., Gramlich, T. and Younossi, Z.M. (2009) Long-Term Follow-Up of Patients with Nonalcoholic Fatty Liver. Clinical Gastroenterology, 7, 234-238. https://doi.org/10.1016/j.cgh.2008.11.005

8. Dunn, W., Xu, R., Wingard, D.L., Rogers, C., Angulo, P., Younossi, Z.M. and Schwimmer, J.B. (2008) Suspected Nonalcoholic Fatty Liver Disease and Mortality Risk in a Population-Based Cohort Study. American Journal of Gastroenterology, 103, 2263-2271. https://doi.org/10.1111/j.1572-0241.2008.02034.x

9. Bhala, N., Angulo, P., Vander, P.D., Lee, E., Hui, J.M., Saracco, G., Adams, L.A., Charatcharoenwitthaya, P., Topping, J.H., Bugianesi, E., Day, C.P. and George, J. (2011) The Natural History of Nonalcoholic Fatty Liver Disease with Advanced Fibrosis or Cirrhosis: An International Collaborative Study. Hepatology, 54, 1208-1216. https://doi.org/10.1002/hep.24491

10. Baffy, G., Brunt, E.M. and Caldwell, S.H. (2012) Hepatocellular Carcinoma in Nonalcoholic Fatty Liver Disease: An Emerging Menace. Journal of Hepatology, 56, 1384-1391. https://doi.org/10.1016/j.jhep.2011.10.027

11. Pais, R., Charlotte, F., Fedchuk, L., Bedossa, P., Lebray, P., Poynard, T. and Ratziu, V. (2013) A Systematic Review of Follow-Up Biopsies Reveals Disease Progression in Patients with Non-Alcoholic Fatty Liver. Journal of 
Hepatology, 59, 550-556.

12. Powell, E.E., Cooksley, W.G., Hanson, R., Searle, J., Halliday, J.W. and Powell, L.W. (1990) The Natural History of Nonalcoholic Steatohepatitis: A Follow-Up Study of Forty-Two Patients for Up to 21 Years. Hepatology, 11, 74-80. https://doi.org/10.1002/hep.1840110114

13. Younossi, Z.M., Otgonsuren, M., Henry, L., Venkatesan, C., Mishra, A., Erario, M. and Hunt, S. (2015) Association of Non-Alcoholic Fatty Liver Disease (NAFLD) with Hepatocellular Carcinoma (HCC) in Unites States from 2004 to 2009. Hepatology, 62, 1723-1730. https://doi.org/10.1002/hep.28123

14. Yilmaz, Y. (2012) Is Nonalcoholic Fatty Liver Disease the Hepatic Expression of the Metabolic Syndrome. World Journal of Hepatology, 4, 332-334. https://doi.org/10.4254/wjh.v4.i12.332

15. Lazo, M., Ruben, H. and Clark, J.M. (2013) Prevalence of Non Alchoholic Fatty Liver Diseases in Unites States: The Third National Health and Nutrition Examination Survey, 1988-1994. American Journal of Epidemiology, 178, 38-45. https://doi.org/10.1093/aje/kws448

16. Cortez-Pinto, H., Camilo, M.E., Baptista, A., DeOliveira, A.G. and Moura, M.C. (1999) Nonalcoholic Fatty Liver Disease: Another Feature of the Metabolic Syndrome. Clinical Nutrition, 18, 353-358. https://doi.org/10.1016/S0261-5614(99)80015-6

17. Loomba, R. and Sanyal, A.J. (2013) The Global NAFLD Epidemic. Hepatology, 10, 686-690. https://doi.org/10.1038/nrgastro.2013.171

18. Sarah, J.W., Gong, I., Kim, R., Levstik, M., Beaton, M. and Tirona, R. (2013) Regulation of Cytochrome P4503A4 in Nonalcoholic Fatty Liver Disease by Fibroblast Growth Factor. Hepatology, 27, 537-548.

19. Weston, S.R., Leyden, W., Murphy, R., Bass, N.M., Bell, B.P., Manos, M.M. and Terrault, N.A. (2005) Racial and Ethnic Distribution of Nonalcoholic Fatty Liver in Persons with Newly Diagnosed Chronic Liver Disease. Hepatology, 41, 372-379. https://doi.org/10.1002/hep.20554

20. Charlton, M.R., Burns, J.M., Pederson, R.A., Watt, K.D., Heimbach, J.K. and Dierkhising, R.A. (2011) Frequency and Outcomes of Liver Transplantation for Nonalcoholic Steatohepatitis in the United States. Gastroenterology, 141, 1249-1253. https://doi.org/10.1053/j.gastro.2011.06.061

21. Rinella, M. and Charlton, M. (2016) The Globalization of Nonalcoholic Fatty Liver Disease: Prevalence and Impact on World Health. Hepatology, 64, 19-22. https://doi.org/10.1002/hep.28524

22. Wong, V.W., Vergniol, J., Wong, G.L., Foucher, J., Chan, H.L., Le Bail, B., Choi, P.C., Kowo, M., Chan, A.W. and Merrouche, W. (2010) Diagnosis of Fibrosis and Cirrhosis Using Liver Stiffness Measurement in Nonalcoholic Fatty Liver Disease. Hepatology, 51, 454-462. https://doi.org/10.1002/hep.23312

23. Patton, H.M., Yates, K., Unalp-Arida, A., Behling, C.A., Huang, T.T.K., Rosenthal, P., Sanyal, A.J., Schimmer, J.B. and Lavine, J.E. (2010) Association between Metabolic Syndrome and Liver Histology among Children with Nonalcoholic Fatty Liver Disease. American Journal of Gastroenterology, 105, 2093-2102.

https://doi.org/10.1038/ajg.2010.152

24. Croke, B. and Sampson, D. (2012) Nonalcoholic Fatty Liver Disease: Implications for Clinical Practice and Health Promotion. The Journal of Nurse Practitioners, 8, 45-50. https://doi.org/10.1016/j.nurpra.2011.07.025

25. Pacifico, L., Cantisani, V., Ricci, P., John, F., Osborn, Schiavo, E., Anania, C., Ferrara, E., Dvisic, G. and Chiesa, D. (2008) Nonalcoholic Fatty Liver Disease and Carotid Atherosclerosis in Children. International Pediatric Research Foundation, 63, 423-427. https://doi.org/10.1203/PDR.0b013e318165b8e7

26. Maheshwari, A. and Thuluvath, P.J. (2006) Cryptogenic Cirrhosis and NAFLD. American Journal of Gastroenterology, 101, 665-668. https://doi.org/10.1111/j.1572-0241.2006.00478.x

27. Mencin, A.A. and Lavine, J.E. (2011) Advances in Pediatric Nonalcoholic Fatty Liver Disease. American Journal of Gastroenterology, 58, 1375-1392. https://doi.org/10.1016/j.pcl.2011.09.005 
28. Amirkalali, B., Poustchi, H., Keyvani, H., Khansari, M.R., Ajaarkosh, H., Maadi, M., Shorabi, M.R. and Zamani, F. (2014) Prevalence of Nonalcoholic Fatty Liver Disease and Its Predictors in North of Iran. Iran Journal of Public Health, 43, 1275-1253.

29. Younossi, Z.M., Koenig, A.B., Abdelatif, D., Fazel, Y., Henry, C. and Wymer, M. (2016) Global Epidemiology of Nonalcoholic Fatty Liver Disease-Meta-Analytic Assessment of Prevalence, Incidence, and Outcomes. Hepatology, 64, 73-84. https://doi.org/10.1002/hep.28431

30. Lu, J., Zhang, J., Du, R., Wang, T., Xu, M., Xu, Y., Wang, W., Bi, Y., Li, D., Chen, Y. and Ning, G. (2016) Age at Menarche Is Associated with the Prevalence of Nonalcoholic Fatty Liver Disease Later in Life. Journal of Diabetes, 9, 53-60. https://doi.org/10.1111/1753-0407.12379

31. Singh, S., Singh, P.P., Singh, A.G., Murad, M.H. and Sanchez, W. (2013) Statins Are Associated with a Reduced Risk of Hepatocellular Cancer: A Systemic Review and Meta-Analysis. Gastroenterology, 144, 323-332. https://doi.org/10.1053/j.gastro.2012.10.005

32. Dowman, J.K., Tomlinson, J.W. and Newsome, P.N. (2010) Pathogenesis of Nonalcoholic Fatty Liver Disease. Hepatology, 103, 71-83. https://doi.org/10.1093/qjmed/hcp158

33. Chiang, D.J., Pritchard, M.T. and Nagy, L.E. (2011) Obesity, Diabetes Mellitus and Liver Fibrosis. American Journal of Gastroenterology, 30, 697-702. https://doi.org/10.1152/ajpgi.00426.2010

34. Jarvinen, Y.H. (2016) Diagnosis of Nonalcoholic Fatty Liver Disease (NAFLD). Diabetologia, 59, 1104-1110. https://doi.org/10.1007/s00125-016-3944-1

35. Lee, R.G. (1989) Nonalcoholic Steatohepatitis: A Study of 49 Patients. Human Pathology, 20, $594-598$. https://doi.org/10.1016/0046-8177(89)90249-9

36. Willner, I.R., Waters, B., Patil, S.R., Reuben, A., Morelli, J. and Riely, C.A. (2001) Ninety Patients with Nonalcoholic Steatohepatitis: Insulin Resistance, Familial Tendency, and Severity of Disease. American Journal of Gastroenterology, 96, 2957-2961. https://doi.org/10.1111/j.1572-0241.2001.04667.x

37. Marchesini, G., Brizi, M., Bianchi, G., Tomassetti, S., Bugianesi, E., Lenzi, M., McCollough, A.J., Natale, S., Forlani, G. and Melchionda, N. (2001) Nonalcoholic Fatty Liver Disease: A Feature of the Metabolic Syndrome. Diabetes, 50, 1844-1850. https://doi.org/10.2337/diabetes.50.8.1844

38. Blackett, P.R. and Sanghera, D.K. (2016) Genetic Determinants of Cardiometabolic Risk: A Proposed Model for Phenotype Association and Interaction. Journal of Clinical Lipidology, 7, 65-81.

https://doi.org/10.1016/j.jacl.2012.04.079

39. Adamo, E., Northurp, V., Weiss, R., Santro, N., Pierpont, B., Savoye, M., O’Malley, G. and Caprio, S. (2010) Ethnic Differences in Lipoprotein Subclasses in Obese Adolescents: Importance of Liver and Intraabdominal Fat Accretion. American Journal of Clinical Nutrition, 92, 500-508. https://doi.org/10.3945/ajcn.2010.29270

40. Solderberg, C., Stal, P., Askling, J., Glaumann, H., Lindaberg, G., Murmur, J. and Hulterantz, R. (2010) Decreased Survival of Elevated Liver Function Test during 28 Year Follow Up. Hepatology, 51, 595-602. https://doi.org/10.1002/hep.23314

41. Sert, A., Pirgon, O., Aypar, E., Yilmaz, H. and Odabas, D. (2012) Relationship between Left Ventricular Mass and Carotid Intima Media Thickness in Obese Adolescents with Non-Alcoholic Fatty Liver Disease. Journal of Pediatric Endocrinology and Metabolism, 25, 927-934. https://doi.org/10.1515/jpem-2012-0187

42. Ekstedt, M., Hagstrom, H., Nasr, P., Fredrikson, M., Stal, P., Kechagias, S. and Hultcrantz, R. (2015) Fibrosis Stage Is the Strongest Predictor for Disease-Specific Mortality in NAFLD after Up to 33 Years of Follow-Up. Hepatology, 61, 1547-1554. https://doi.org/10.1002/hep.27368

43. Laurin, J.I., Lindor, K.D., Crippin, J.S., Gossard, A., Gores, G.J., Ludwig, J., Rakela, J. and McGill, D.B. (1996) Ursodeoxycholic Acid or Clofibrate in the Treatment of Non-Alcohol-Induced Steatohepatitis: A Pilot Study. Hepatology, 23, 1464-1467. https://doi.org/10.1002/hep.510230624 
44. Matteoni, C.A., Younossi, Z.M., Gramlich, T., Boparai, N., Liu, Y.C. and McCullough, A.J. (1999) Nonalcoholic Fatty Liver Disease: A Spectrum of Clinical and Pathological Severity. Gastroenterology, 116, 1413-1419. https://doi.org/10.1016/S0016-5085(99)70506-8

45. Angulo, P., Keach, J.C., Batts, K.P. and Lindor, K.D. (1999) Independent Predictors of Liver Fibrosis in Patients with Nonalcoholic Steatohepatitis. Hepatology, 30, 1356-1362. https://doi.org/10.1002/hep.510300604

46. Chitturi, S., Abeygunasekera, S., Farrell, G.C., Holmes-Walker, J., Hui, J.M., Fung, C., Karim, R., Lin, R., Samarasinghe, D., Liddle, C. and Weltman, M. (2002) NASH and Insulin Resistance: Insulin Hypersecretion and Specific Association with the Insulin Resistance Syndrome. Hepatology, 35, 373-379.

https://doi.org/10.1053/jhep.2002.30692

47. Evans, C., Oien, K., MacSween, R. and Mills, P. (2002) Non-Alcoholic Steatohepatitis: A Common Cause of Progressive Chronic Liver Injury? Journal of Clinical Pathology, 55, 689-692. https://doi.org/10.1136/jcp.55.9.689

48. Vernon, G., Baranova, A. and Younossi, Z.M. (2011) The Epidemiology and Natural History of Nonalcoholic Fatty Liver Disease and Nonalcoholic Steatohepatitis in Adults. Alimentary Pharmacology and Therapeutics, 34, 274-285. https://doi.org/10.1111/j.1365-2036.2011.04724.x

49. Kabbany, M.N., Selvakumar, P.K.C., Watt, K., Lopez, R. Akras, Z., Zein, N., Carey, W. and Alkhouri, N. (2017) Prevalence of Nonalcoholic Steatohepatitis-Associated Cirrhosis in the United States: An Analysis of National Health and Nutrition Examination Survey Data. American College of Gastroenterology, 3, 1-7.

50. Kanwal, F., Kramer, J.R., Duan, Z., Yu, X., White, D. and El-Serag, H.B. (2016) Trends in the Burden of Non-Alcoholic Fatty Liver Disease in a US Cohort of Veterans. Clinical Gastroenterology Hepatology, 14, 301-308. https://doi.org/10.1016/j.cgh.2015.08.010

51. Harrison, S.A., Torgerson, S. and Hayashi, P.H. (2003) The Natural History of Nonalcoholic Fatty Liver Disease: A Clinical Histopathological Study. American Journal of Gastroenterology, 98, 2042-2047. https://doi.org/10.1111/j.1572-0241.2003.07659.x

52. Liangpunsakul, S. and Chalasani, N. (2005) Unexplained Elevations in Alanine Aminotransferase in Individuals with the Metabolic Syndrome: Results from the Third National Health and Nutrition Survey (NHANES III). American Journal of Medical Science, 329, 111-116. https://doi.org/10.1097/00000441-200503000-00001

53. Day, C.P. (2012) Clinical Spectrum and Therapy of Non-Alcoholic Steatohepatitis. Digestive Disease and Science, 1, 69-73. https://doi.org/10.1159/000341128

54. Bonci, E., Chiesa, C., Versacci, P., Anania, C., Silvestri., L. and Pacifio, L. (2015) Association of Nonalcoholic Fatty Liver Diseases with Subclinical Cardio Vascular Changes. Biomedical Research International, 8, 1-11. https://doi.org/10.1155/2015/213737

55. Gambarin, G.M., Kinkhabwala, S.V., Schiano, T.D., Bodian, C., Yeh, H.C. and Futterweit, W. (2007) Spectrum of NAFLD and Diagnostic Implications of the Proposed New Normal Range for Serum ALT in Obese Women. Hepatology, 42, 650-656.

56. Williams, C.D., Stengel, J., Asike, M.I., Torres, D.M., Shaw, J., Contreras, M., Landt, C.L. and Harrison, S.A. (2011) Clinical Advances in Liver, Pancreas and Biliary Tract. Gastroenterology, 140, 124-131. https://doi.org/10.1053/j.gastro.2010.09.038

57. Bambha, K., Belt, P., Abraham, M., Wilson, L.A., Pabst, M., Ferrell, L., Unalp-Arida, A. and Bass, N. (2012) Ethnicity and Nonalcoholic Fatty Liver Disease. Hepatology, 55, 769-780. https://doi.org/10.1002/hep.24726

58. Caserta, C.A., Mele, A., Surace, P., Ferrigno, L., Amante, A., Messineo, A., Vacalabre, C., Amato, F., Baldassare, D., Amato, M., Marcucci, F. and Zuin, M. (2017) Association of NAFLD and Cardio Metabolic RISL Factor with Early Artherosclerosis in an Adult Population in South Italy. Cardiovascular and Metabolic Risk, 53, 77-81. 
59. Kulkina, E.V., Carroll, M.D., Shaw, K.M. and Hirschi, R. (2013) Trends in High LDL Cholesterol, Cholesterol Lowering Medication and Dietary Saturated Fat Intake in United States 1976-2010. Gastroenterology, 117, 1-8.

60. McPherson, S.T., Hardy, M.T., Henderson, E., Burt, A.D., Day, C.P. and Anstee, Q.M. (2015) Evidence of NAFLD Progression from Steatosis to Fibrosing-Steatohepatitis Using Paired Biopsies: Implications for Prognosis and Clinical Management. Journal of Hepatology, 62, 1148-1155. https://doi.org/10.1016/j.jhep.2014.11.034

61. Dassanayake, A.S., Kasthuriaratne, A., Rajendrajith, S., Kalubowila, V., Chakrawarthi, S., DeSilva, A.P., Makaya, M., Mizove, T., Kato, N., Wickramasinghe, A.R. and Desilva, H.J. (2009) Prevalence and Risk Factors for Non-Alcoholic Fatty Liver Disease among Adults in an Urban Srilankan Population. Journal of Gastroenterology and Hepatology, 24, 1284-1288. https://doi.org/10.1111/j.1440-1746.2009.05831.x 